\title{
Correction to: Distribution and association of agro-ecological factors influencing garlic rust (Puccinia allii) epidemics in Eastern Amhara, Ethiopia
}

\author{
Zemenu Endalew $^{1} \cdot$ Habtamu Terefe $^{2}$ (D) $\cdot$ Mashilla Dejene $^{2} \cdot$ Alok Kumar $^{3}$
}

Published online: 2 March 2021

(c) Indian Phytopathological Society 2021

\section{Correction to: Indian Phytopathology https://doi.org/10.1007/s42360-020-00297-w}

The original version of this article unfortunately contained a mistake. The presentation of equations was incorrect. The corrected equations are given below.

The original article has been corrected.

Prevalence $(\%)=\frac{\text { Number of fields showing rust symptom }}{\text { Total number of fields visited }} \times 100$

Incidence $(\%)=\frac{\text { Number of plants infected in the quadrat }}{\text { Total number of plants in the quadrat }} \times 100$

PSI $=\frac{\text { Sum of numerical ratings }}{\text { Total number of plants scored } \times \text { maximum score on scale }} \times 100$

The original article can be found online at https://doi.org/10.1007/ s42360-020-00297-w.

Habtamu Terefe

habmam21@gmail.com

1 Sekota Dryland Agricultural Research Center, ARARI, P.O.

Box 62, Sekota, Ethiopia

2 Plant Protection Program, School of Plant Sciences,

Haramaya University, P.O. Box 138, Dire Dawa, Ethiopia

3 Plant Breeding and Genetics Program, School of Plant Sciences, Haramaya University, P.O. Box 138, Dire Dawa, Ethiopia 